\title{
Hirschsprung's disease associated with a deletion of chromosome 10 (q11.2q21.2): a further link with the neurocristopathies?
}

\author{
M S Fewtrell, P K H Tam, A H Thomson, M Fitchett, J Currie, S M Huson, \\ L M Mulligan
}

\begin{abstract}
We report a patient with total colonic aganglionosis in association with a deletion of part of the long arm of chromosome 10: (del(10)(q11.2q21.2)). This deletion includes the ret proto-oncogene, which has recently been implicated in multiple endocrine neoplasia type $2 A$ (MEN 2A). The possible links between Hirschsprung's disease and the neurocristopathies and the aetiological role of abnormalities of neural crest development in these conditions are discussed.
\end{abstract}

( $(\mathcal{M}$ Med Genet 1994;31:325-327)

Hirschsprung's disease (HD) occurs in approximately 1 in 5000 infants with an overall male predominance $(5: 1)$. However, the sex ratio decreases and the recurrence risk to sibs increases as the aganglionosis becomes more extensive. In the $4 \%$ of patients with total colonic aganglionosis (TCA) the sex incidence is equal. Badner et $a l^{1}$ have suggested, on the basis of a large pedigree analysis, that a dominant gene or several different dominant genes with incomplete penetrance play a role in the aetiology of HD extending beyond the sigmoid colon. However, the mode of inheritance for shorter segment HD is less clear. Several conditions have been noted in association with $\mathrm{HD}$, mostly in single case reports. Among these are reports of HD in patients with neurocristopathies, including MEN type $2 \mathrm{~A}^{2-4}$ We report a case with TCA and a deletion in the proximal long arm of chromosome 10, which includes the gene for MEN type $2 \mathrm{~A} .^{5}$ We are aware of one previously reported similar case. ${ }^{6}$

\section{Case report}

A female infant was born at term weighing $2700 \mathrm{~g}$ (below the $3 \mathrm{rd}$ centile), the only child of healthy, unrelated parents, with no significant family history. At the age of 24 hours she developed bile stained vomiting and had not passed meconium. Laparotomy showed a volvulus, apparently associated with meconium ileus, and $20 \mathrm{~cm}$ of terminal ileum was resected. The infant was thought to have cystic fibrosis, although initial sweat testing was equivocal, and she was negative for the common gene mutations. Postoperatively she thrived, although with intermittent vomiting.

At the age of 3 months the child presented with small bowel obstruction. Laparotomy showed a dilated small bowel with an apparently normal colon. Rectal biopsy was thought to contain ganglion cells, although the specimen was poorly preserved. An ileostomy was formed, and the child thrived. Reversal of ileostomy was performed at the age of 8 months, but small bowel obstruction occurred in the immediate postoperative period, necessitating a further ileostomy. Colonic biopsy showed complete absence of ganglion cells at all sites sampled, confirming a diagnosis of total colonic Hirschsprung's disease. Sweat test at this stage was normal.

Resected ileum was cultured for DNA investigations because of persisting uncertainty over the possible diagnosis of cystic fibrosis. Cytogenetic analysis, performed routinely on cells cultured for molecular studies, showed an interstitial deletion from the proximal long arm of chromosome 10 (46,XX, del (10)(q11)). This was subsequently confirmed on a blood specimen as del (10)(q11.2q21.2) (figure). Both parents had normal karyotypes.

The limits of the deletion were further refined by DNA hybridisation analyses using DNA markers mapped to chromosome 10q. High molecular weight DNA isolated from cultured fibroblasts was digested with appropriate restriction enzymes, fractionated by gel electrophoresis, transferred to nylon membranes, and hybridised to probes for the chromosome 10 region, as previously described. ${ }^{78}$ The probe loci examined and their chromosomal positions are indicated in the table. Densitometric comparisons of allele intensities for loci on chromosome $10 \mathrm{q}$ and on chromosome 17 (NF1) were performed for the patient and for three normal control samples. Two copies of each locus were present in each control DNA sample. In DNA from the patient, a single copy of loci distal to D10S141 and proximal to D10S5 were detected. Two copies of all other chromosome 10 loci and of control loci on chromosome 17 were present.
Correspondence to
Dr Fewtrell,
Department of Paediatrics,
Addenbrooke's Hospital,
Cambridge CB2 2QQ, UK.
Received 1 July 1993
Revised version accepted for
publication 11 November
1993

Correspondence to
Dr Fewtrell,
Department of Paediatrics,
Addenbrooke's Hospital,
Cambridge CB2 2QQ, UK.
Received 1 July 1993
Revised version accepted for
publication 11 November
1993

Correspondence to
Dr Fewtrell,
Department of Paediatrics,
Addenbrooke's Hospital,
Cambridge CB2 2QQ, UK.
Received 1 July 1993
Revised version accepted for
publication 11 November
1993 


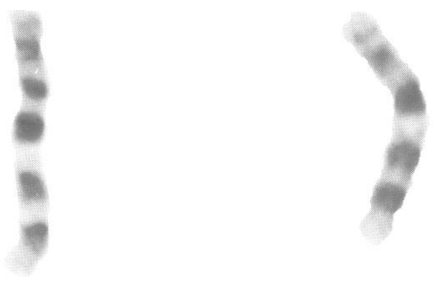

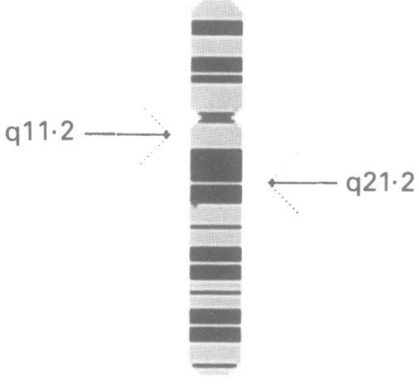

10

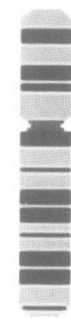

del (10)
Partial karyotype of the patient showing del (10) (q11.2q21.2)

These data are summarised in the table. Our results suggest that the proximal deletion limit in the patient lies in 10q11.2 between the D10S141 locus and the ret proto-oncogene. The distal breakpoint lies in 10q21 between D10S5 and D10S22. The molecular size of this deletion is difficult to estimate, but it spans a genetic distance of more than $25 \mathrm{cM}$ (sex averaged). ${ }^{10}$ Recent genetic linkage analyses have suggested that a gene for familial Hirschsprung's disease may lie within this region. ${ }^{11} 12$

The patient underwent a Martin-Duhamel pull through at the age of 18 months, with closure of her ileostomy eight weeks later. Her subsequent course was complicated by malabsorption requiring a prolonged period of parenteral nutrition. However, she is now fully enterally fed with weight just below the 3rd centile.

Apart from her bowel problems, the patient is healthy with no dysmorphic features. However, her occipitofrontal circumference increased from the 50th centile at birth to above the 90 th centile at 1 year, and cranial CT

Deletion of chromosome 10 markers in our patient with Hirschsprung's disease

\begin{tabular}{lll}
\hline Locus* & Location* & Hirschsprung's patient \\
\hline ZNF33B & 10q11.2 & + \\
D10S97 & $10 \mathrm{q} 11.2$ & + \\
D10S141 & $10 \mathrm{q} 11.2$ & + \\
RET & $10 \mathrm{q} 11.2$ & - \\
D10S94 & $10 \mathrm{q} 11.2$ & - \\
D10S102 & $10 \mathrm{q} 11.2$ & - \\
D10S30 & $10 \mathrm{q} 11.2$ & - \\
RBP3 & $10 \mathrm{q} 11.2$ & - \\
D10S15 & $10 \mathrm{q} 11.2$ & - \\
D10S5 & $10 \mathrm{q} 21.1$ & - \\
D10S22 & $10 \mathrm{q} 21.1$ & + \\
CHAT & $10 \mathrm{q} 11.2-\mathrm{q} 22.1$ & + \\
D10S170 & $10 \mathrm{q} 21$ & + \\
NF1 & $17 \mathrm{q} 11.2$ & + \\
\hline
\end{tabular}

$+=$ locus not deleted, $-=$ locus present in only one copy.

*Information regarding these loci is described by Williamson $e$ al. . $^{9}$ scan showed mildly enlarged lateral and fourth ventricles. The occipitofrontal circumference has increased steadily along the 97 th centile, and further intervention has not been required. Developmental assessment at the age of 30 months indicated a cognitive level of 21 months with a greater motor delay. At least part of this is felt to be because of her prolonged hospitalisation.

\section{Discussion}

Hirschsprung's disease results from congenital absence of intramural ganglia affecting the rectum with variable proximal extension. Despite advances in the treatment of the condition, its pathogenesis remains uncertain. Current evidence favours an abnormality in the microenvironment of the embryonic bowel resulting in abnormal migration or differentiation of primitive neural crest cells. ${ }^{13}$ In one mouse model of $\mathrm{HD}$, the lethal spotted mouse, the distal $2 \mathrm{~mm}$ of bowel fails to innervate normally ${ }^{14}$ and this section of the bowel is not colonised by neural crest cells from a variety of sources. ${ }^{15}$

Congenital megacolon occurs in the mouse, rat, and horse, and is considered to be a model for $\mathrm{HD}$ in man. In each case, a single gene mutation is responsible. Interestingly, in the piebald-lethal mouse model the locus is on chromosome 14, whose proximal long arm is homologous to human chromosome $10 \mathrm{q} 11 \mathrm{q} 21 .{ }^{16}$ In humans, familial cases of HD are well recognised, and a recent analysis of 487 patients and their families concluded that the mode of inheritance is compatible with one or more defective single genes with variable penetrance, at least for long segment disease. ${ }^{1}$ $\mathrm{HD}$ has been reported in association with various conditions, including a deletion of chromosome $13 .{ }^{17} 18$ It has also been described in association with neuroblastoma, neurofibromatosis type 1 , phaeochromocytoma, and congenital central hypoventilation, ${ }^{23}$ as well as with multiple endocrine neoplasia type $2 \mathrm{~A}$ (medullary carcinoma of the thyroid, phaeochromocytoma, and parathyroid hyperplasia). ${ }^{4}$ All of these conditions may be classified as neurocristopathies, or conditions originating from abnormal development of neural crest cells.

To our knowledge, our patient is the second case of total colonic HD reported with a deletion in the long arm of chromosome 10. The other patient, an Italian girl with a $46, \mathrm{XX}$,del (10) (q11.21q21.2) karyotype, is developmentally normal at the age of $2 \frac{1}{2}$ years, with no other obvious abnormalities apart from total colonic aganglionosis. ${ }^{6}$ These cases are of particular interest as the chromosome 10 deletion includes the ret proto-oncogene. Mutations of ret are the underlying cause of MEN 2A and familial medullary thyroid carcinoma. Verdy $e t$ $a l^{4}$ found HD in eight of his series of 92 patients with MEN 2A, but we are not aware of any cytogenetic analyses in these cases. Interstitial deletions of $10 \mathrm{q}$ are uncommon. Three patients have been reported with deletions in the same region as our patient. The 
children described by Lobo et $a l^{19}$ $(\operatorname{del}(10)(\mathrm{q} 11.1 \mathrm{q} 22.1))$ and Ray et $a l,{ }^{20}$ (del(10)(q11q21)) both had dysmorphic features including a broad forehead and hypertelorism, together with hypotonia and psychomotor delay. The patient described by Holden and MacDonald ${ }^{21}$ (del(10)(q11.2q21)) had developmental delay, hypotonia, and seizures. However, bowel abnormalities were not reported in any of the cases. It is difficult to be certain from the cytogenetic studies presented how these deletions correspond to that in our patient, and it would be interesting to define them further by DNA analysis.

Attention has focused recently in mice, and other animals, on the role of homeobox and Pax genes in regulating development and cellular differentiation. Wolgemuth et $a l^{22}$ have shown overexpression of the homeobox containing gene Hox-1.4 in the embryonic gut of mice, associated with congenital megacolon. More recently, Tassabehji et $a l^{23}$ have shown that some families with Waardenburg's syndrome (a condition probably resulting from abnormal neural crest development) have mutations in the human homologue of the mouse Pax-3 gene. Mutation in the murine gene affects structures derived from the neural crest. The deletion in our patient spans the ret protooncogene, mutation of which has been implicated in the neurocristopathies MEN 2A and familial medullary thyroid carcinoma. Recently, genetic linkage analyses in families with HD have shown that a gene for an inherited form of the disease lies in 10q11.2, close to the ret locus. ${ }^{11}{ }^{12}$ Taken together these data suggest that the ret proto-oncogene is a strong candidate gene for $\mathrm{HD}$. Therefore, further analysis of chromosome 10 in patients with $\mathrm{HD}$, particularly those with total colonic involvement or associated neurocristopathies, is warranted to investigate this possibility.

1 Badner J, Sieber W, Garver K, et al. A genetic study of Hirschsprung's disease. Am $\mathcal{F}$ Hum Genet 1990;46:56880.

2 Clausen N, Andersson P, Tommerup N. Familial occurrence of neuroblastoma, Von Recklinghausen's neurofibromatosis, Hirschsprung's aganglionosis and jaw winking syndrome. Acta Paediatr Scand 1989;78:736-41.
3 Levard G, Boige N, Viyoux C, et al. Neurocristopathy. The association of Hirschsprung's disease-ganglioneuroma with autonomic nervous system dysfun

4 Verdy M, Weber AM, Roy CC, et al. Hirschsprung's disease in a family with MEN type 2. $\mathcal{F}$ Paediatr Gastroenterol Nur 1982;1:603-7.

5 Mulligan L, Kwok J, Healey C, et al. Germline mutations of the RET proto-oncogene in multiple endocrine neoplasia type 2A (MEN 2A). Nature 1993;363: 458-60.

6 Martucciello G, Bicocchi MP, Dodero P, et al. Total colonic aganglionosis associated with interstitial deletion of the long arm of chromosome 10. Pediatr Surg Int 1992;7:308-10.

7 Matthew CGP, Smith BA, Thorpe K, et al. Deletion of genes on chromosome 1 in endocrine neoplasia. Nature 1987;328:524-6.

8 Mulligan LM, Gardner E, Smith BA, et al. Genetic events in tumour initiation and progression in multiple endo-

crine neoplasia type 2. Genes Chrom Canc 1993;6:166-7. Williamson R, Bowcock A, Kidd K, et al. Report of the DNA committee and catalogues of cloned and mapped gene markers formatted for PCR and DNA polymor-
phisms. Cytogenet Cell Genet 1991;58:1190-1832.

10 Lichter JB, Difilippantonio MJ, Pakstis AJ, et al. Physical and genetic maps for chromosome 10. Genomics 1993;16:320-4.

11 Angrist M, Kaufman E, Slaugenhaupt SA, et al. A gene for Hirschsprung's disease (megacolon) in the pericentromeric region of human chromosome 10. Nature Genet 1993;4:351-6.

12 Lyonnet S, Bolino A, Pelet A, et al. A gene for Hirschsprung's disease maps to the proximal long arm of chromosome 10. Nature Genet 1993;4:346-50.

13 Lister J, Tam PKH. Hirschsprung's disease. In: Lister J, Irving IM, eds. Neonatal surgery. Chap 37. London; Butterworth, 1990:523-41.

14 Nishijima E, Carel Meijers JH, Tibboel D, et al. Formation and malformation of the enteric nervous system in mice: an organ culture study. $\mathcal{F}$ Paediatr Surg 1990;25:627-31.

15 Jacobs-Cohen RJ, Payette RF, Gershon MD, et al. InabiJacobs-Cohen RJ, Payette RF, Gershon MD, et al. Inabi-
lity of neural crest cells to colonize the presumptive lity of neural crest cells to colonize the presumptive
aganglionic bowel of $1 \mathrm{~s} / \mathrm{ls}$ mutant mice: requirement for a aganglionic bowel of ls/ls mutant mice: requirement for a
permissive microenvironment. $f$ Comp Neurol permissive mic

16 Lane P. Association of megacolon with two recessive spotting genes in the mouse. $\mathcal{f}$ Hered 1966;57:29-31.

17 Bottani A, Xiey G, Bunkert F, et al. A case of Hirschsprung's disease with a chromosome 13 microdeletion, del (13) (q32.3q33.2): potential mapping of one disease locus. Hum Genet 1991;87:748-50.

18 Lamont MA, Fitchett M, Dennis NR. Interstitial deletion of distal 13q associated with Hirschsprung's disease. $\mathcal{f}$ Med Genet 1989;26:100-4.

19 Lobo S, Cervenka J, London A, et al. Interstitial deletion of 10q: clinical features and literature review. $\mathrm{Am} \mathcal{F} \mathrm{Med}$ Genet 1992;43:701-3.

20 Ray M, Hunter A, Josifek K. Interstitial deletion of the long arm of chromosome 10. Ann Genet (Paris) 1980; 23: 1034.

21 Hoiden JA, MacDonald EA. Brief clinical report. Interstitial deletion of the long arm of chromosome 10: del (10)(q11.2q21) Am $\mathcal{F}$ Med Genet 1985;20:245-9.

22 Wolgemuth DJ, Behringer RR, Mostoller MP, et al. Transgenic mice overexpressing the mouse homoebox-containing gene Hox-1.4 exhibit abnormal gut development. ing gene Hox-1.4 exhibit

23 Tassabehji M, Read AP, Newton VE, et al. Waardenburg's syndrome patients have mutations in the human homologue of the Pax-3 paired box gene. Nature 1992;355:635- 